\title{
The Carbon monoxide releasing molecule ALF-186 mediates anti-inflammatory and neuroprotective effects via the soluble guanylate cyclase $B 1$ in rats' retinal ganglion cells after ischemia and reperfusion injury
}

Felix Ulbrich', Claus Hagmann ${ }^{1}$, Hartmut Buerkle ${ }^{1}$, Carlos C. Romao ${ }^{3,4}$, Nils Schallner ${ }^{1}$, Ulrich Goebel ${ }^{1{ }^{*}+}$ (I) and Julia Biermann ${ }^{2 \dagger}$

\begin{abstract}
Background: The endogenously produced gaseous molecule carbon monoxide is able to promote organ protection after ischemia-reperfusion injuries (IRI). The impact of carbon monoxide releasing molecules (CORM) regarding inflammation in neuronal tissues has not been studied in detail. In this investigation, we aimed to analyze the effects of the CORM ALF-186 on neuro-inflammation and hypothesized that the soluble guanylate cyclase (sGC) is playing a decisive role.

Methods: Retinal ischemia-reperfusion injury was performed for 60 min in Sprague-Dawley rats. Thereafter, the CORM ALF-186 $(10 \mathrm{mg} / \mathrm{kg})$ in the presence or absence of the sGC inhibitor ODQ was injected via a tail vein. Retinal tissue was harvested $24 \mathrm{~h}$ later to analyze mRNA or protein expression of SGC- $\beta 1$ subunit, transcription factors NF-KB and CREB, the inflammatory cytokines TNF- $a$ and IL-6, as well as the heat shock proteins (HSP) HSP-70 and HSP-90. Immunohistochemistry was performed on frozen sections of the retina. The overall neuroprotective effect of ALF-186 was assessed by counting fluorogold-pre-labeled retinal ganglion cells (RGC) 7 days after IRI.

Results: Ischemia-reperfusion mediated loss of vital RGC was attenuated by the administration of ALF-186 after injury. ALF-186 treatment after IRI induced SGC- $B_{1}$ leading to a decreased NF-KB and CREB phosphorylation. Consecutively, ALF-186 mitigated IRI induced TNF- $a$ and IL-6 expression in the retina and in the rats' serum. Moreover, ALF-186 attenuated heat shock protein 70 ( $\mathrm{Hsp}-70)$ while increasing Hsp-90. The SGC-inhibitor ODQ attenuated the antiinflammatory effects of ALF-186 and increased retinal loss of ganglion cells. These results were confirmed by immunohistochemistry.
\end{abstract}

(Continued on next page)

\footnotetext{
*Correspondence: ulrich.goebel@uniklinik-freiburg.de

${ }^{\dagger}$ Equal contributors

${ }^{1}$ Department of Anesthesiology and Critical Care, Medical Center, University of Freiburg, Faculty of Medicine, University of Freiburg, Hugstetter Strasse 55, D-79106 Freiburg, Germany

Full list of author information is available at the end of the article
} 
(Continued from previous page)

Conclusion: The CORM ALF-186 protected RGC from IRI induced loss. Furthermore, ALF-186 reduced IRI mediated neuroinflammation in the retina and in the serum by activating sGC. Inhibition of sGC stopped the beneficial and protective effects of ALF-186. ALF-186 may present a promising therapeutic alternative in treating inflammation after neuronal IRI.

Keywords: Ischemia/reperfusion injury, Carbon monoxide, Neuro-inflammation, Neuroprotection, sGC- $\beta_{1}$, Heat shock proteins

\section{Background}

Exogenously administered carbon monoxide ameliorates injuries of various organs like the heart, lung, kidney, and liver. Efficiency of inhaled carbon monoxide [1] and carbon monoxide releasing molecule (CORM), given before or after injury, has been proven in many animal models using ischemia-reperfusion injury (IRI), transplantation, or sepsis [2-8]. Interfering with physiological intracellular processes $\mathrm{CO}$ affects among others inflammation and apoptosis leading to reduced cell death $[9,10]$. However, CO's impact on neuronal tissue is less well investigated and the underlying mechanisms have not been fully understood.

Ischemic injury in neurons after stroke or traumatic brain injury is one of the leading causes of mortality. Due to high sensitivity of insufficient blood flow and oxygen supply of neurons as well as limited regeneration ability, ischemic injury is frequently associated with poor neurological outcome [11-13]. Therefore, restoration and maintenance of cerebral circulation must be the primary goal of treatment.

Since there is currently no reliable medical opportunity for mitigating neuronal injury, $\mathrm{CO}$ might be a possible agent for this approach.

Querioga et al. showed in their study that inhaled carbon monoxide as a preconditioning agent provides neuroprotection following perinatal hypoxia-ischemia [14]. Given before injury, carbon monoxide exerts its protective effect, at least in part, via the soluble guanylate cyclase (sGC) [1]. As an endogenous receptor for nitric oxide sGC is activated by CO-binding on its heme groups and catalyzes cGMP activation [15].

We hypothesize that the CORM ALF-186 would reduce neuroinflammation after retinal IRI and mediate neuroprotective effects via the sGC pathway.

\section{Methods}

\section{Animals}

Adult male and female Sprague-Dawley rats (1:1, 280350 g bodyweight, Charles River, Sulzfeld, Germany) were used in these experiments. Animals were fed with a standard diet ad libitum, being kept on a $12 \mathrm{~h}$ light/12 h dark cycle. All procedures involving animals concurred with the statement of The Association for Research in
Vision and Ophthalmology for the use of animals in research in accordance with the ARRIVE guidelines and were approved a priori by the Committee of Animal Care of the University of Freiburg (Permit No: 35-9185.81/ G-11/81). All types of surgery and manipulations were performed under general anesthesia with isoflurane $/ \mathrm{O}_{2}$ for retrograde labeling with fluorogold (FG) or with a mixture of intraperitoneally administered ketamine $50 \mathrm{mg} / \mathrm{kg}$ (Ceva-Sanofi, Duesseldorf, Germany) and xylazine $2 \mathrm{mg} /$ $\mathrm{kg}$ (Ceva-Sanofi) for the ischemia-reperfusion experiment. Body temperature was maintained at $37 \pm 0.5{ }^{\circ} \mathrm{C}$ with a heating pad. After surgery, buprenorphine (Temgesic ${ }^{\circ}$ $0.5 \mathrm{mg} / \mathrm{kg}$; Essex Pharma, Solingen, Germany) was applied intraperitoneally to prevent pain. During recovery from anesthesia, the animals were placed in separate cages. The number of animals used for RGC quantification and molecular analysis was $n=8$ per group. For analysis of mRNA- and protein-expression, retinal tissue was harvested at $t=24 \mathrm{~h}$ after reperfusion.

\section{Retrograde labeling of RGC}

Sprague Dawley rats were anesthetized, placed in a stereotactic apparatus (Stoelting, Kiel, Germany) and retrograde RGC-labeling was done as described previously [16], briefly summarized as follows. The skin overlying the skull was cut open und retracted. The lambda and bregma sutures served as landmarks for drilling three holes on each site of the bregma sutures. A total amount of $7.8 \mu \mathrm{l}$ fluorogold (FG) (Fluorochrome, Denver, $\mathrm{CO}$, USA) dissolved in DMSO/PBS was injected into both superior colliculi through the drilling holes. To ensure adequate retrograde transport of FG into the RGC's perikarya, further experimental interventions were done 7 days after retrograde labeling.

\section{Retinal ischemia/reperfusion injury and treatment with ALF-186}

Following randomization, rats were sedated and the anterior chamber of the left eye was cannulated with a 30 -gauge needle connected to a reservoir containing $0.9 \% \mathrm{NaCl}$. Intraocular pressure was increased to $120 \mathrm{~mm} \mathrm{Hg}$ for $60 \mathrm{~min}$ and ocular ischemia was confirmed microscopically by interruption of the retinal circulation. Reperfusion was initiated by removing the needle 
tip promptly. Rats without immediate recovery of retinal perfusion at the end of the ischemic period or those with lens injuries were excluded from the study, since the latter prevents RGC death and promotes axonal regeneration. To evaluate a neuroprotective effect of carbon monoxide released from ALF-186, animals were randomly assigned to receive treatment either with ALF-186 (10 mg/kg body weight i.v., dissolved in water) or water (vehicle control) alone. Both were injected immediately after IRI or with a delay of $3 \mathrm{~h}$ to IRI. Inactivated ALF-186 (iALF-186) was used $24 \mathrm{~h}$ after dissolving to exclude crucial effects of the molybdenum heavy metal backbone. Inactivated ALF186 (iALF) was produced by dissolving ALF-186 in PBS and allowing the liquid solution to stand overnight open to room air and accessible for light. In this time, ALF-186 was able to release CO from its chemical structure, leaving only the heavy-metal backbone (i.e. molybdenum) inside the solution. Prior to the experiments where iALF was used as a negative control, the solution was bubbled with nitrogen, to remove any possible $\mathrm{CO}$-molecules that might have been left in the solution. After that, ALF-186 rested for another hour.

In further experiments, rats received $60 \mathrm{~min}$ prior to IRI the sGC inhibitor ODQ $(2.5 \mathrm{mg} / \mathrm{kg}$ bodyweight i.v., Sigma-Aldrich, Taufkirchen, Germany, \#O2626).

\section{RGC quantification}

Animals were sacrificed by $\mathrm{CO} 2$-inhalation 7 days after ischemia. Retinal tissue was immediately harvested, placed in ice-cold Hank's balanced salt solution and further processed for whole mount preparation. Retinae were carefully placed on a nitrocellulose membrane with the ganglion cell layer (GCL) on top. After removing the vitreous body, retinae were fixed in $4 \%$ paraformaldehyde for $1 \mathrm{~h}$ and then embedded in mounting media (Vectashield; Axxora, Loerrach, Germany). The densities of FG-positive RGC were determined in blinded fashion using a fluorescence microscope (AxioImager; Carl Zeiss, Jena, Germany) and the appropriate bandpass emission filter (FG: excitation/emission, 331/418 nm), as previously described [16]. Briefly, we photographed 3 standard rectangular areas $\left(0.200 \times 0.200 \mathrm{~mm}=0.04 \mathrm{~mm}^{2}\right)$ at 1,2 , and $3 \mathrm{~mm}$ from the optic disc in the central regions of each retinal quadrant. Hence, we evaluated an area of $0.48 \mathrm{~mm}^{2}$ per retina. To calculate the average RGC density in cells $/ \mathrm{mm} 2$, we multiplied the number of analyzed cells $/ 0.04 \mathrm{~mm}^{2}$ with 25 . Secondary fluorogold stained activated microglia cells (AMC) after RGC phagocytosis were identified by morphologic criteria and excluded from calculation. All data are presented as mean RGC densities $\left[\right.$ cells $\left./ \mathrm{mm}^{2}\right] \pm \mathrm{SD}$.

\section{Immunohistochemical staining}

Eyes were enucleated $24 \mathrm{~h}$ after intervention and immediately placed in $4 \%$ paraformaldehyde overnight at $4{ }^{\circ} \mathrm{C}$. After washing in Dulbecco's phosphate buffered saline (D-PBS) before and after postfixation in 30\% sucrose for $5-6 \mathrm{~h}$ at room temperature, eyes were embedded in compound (Tissue-Tek; Sakura-Finetek, Torrance, CA, USA) and frozen in liquid nitrogen. Frozen serial sections $(10 \mu \mathrm{m})$ were cut through the middle third of the eye and collected on gelatinized slides. Immunolabeling was performed according to standardized protocols with primary antibodies against soluble Guanylate Cyclase $\beta_{1}$ (\#160897; rabbit, dilution 1:1500; Cayman Chemical, Ann Arbor, Michigan, USA), TNF- $\alpha$ and Hsp-90 (\#ab6671 and \#ab19021; rabbit, dilution 1:200; both Abcam, Cambridge, UK), IL-6 (\#LS-C70904/65996; rabbit, dilution 1:600; Biozol, Eching, Germany) and Brn-3 (\#sc-390078; rabbit, dilution 1:200; Santa Cruz Biotechnology, Dallas, TX, USA). Primary antibodies were then conjugated with their corresponding secondary antibody (red fluorescence: \#211-605-109, Alexa Fluor 647, mouse anti-rabbit, dilution 1:1000; green fluorescence: \#705-225-147, Cyanine $\mathrm{Cy}^{\mathrm{TM}} 2$, donkey anti-goat, dilution 1:1000; \#111-225-045, Cyanine $\mathrm{Cy}^{\mathrm{TM}} 2$, goat anti-rabbit, dilution 1:1000; all Jackson ImmunoResearch Europe, Newmarket, UK). The nuclei of cells in the retina were stained with 4',6-diamino-2-phenylindole dihydrochloride hydrate (DAPI, Sigma, Taufkirchen, Germany) added to the embedding medium (Mowiol; Calbiochem, San Diego, CA, USA). Slides were examined under a fluorescence microscope (Axiophot; Carl Zeiss, Jena, Germany).

Quantification and histogram analysis of immunostained images was performed using the ImageJ open source software (ImageJ, Version 2.00-rc-44/1.50e, open source image processing software).

\section{Western Blot analysis}

$24 \mathrm{~h}$ after ischemia retinal tissue for analysis of protein expression was harvested. Total protein from $3 / 4$ of retina was extracted and processed for Western Blot as described previously. The membranes were blocked with $5 \%$ skim milk in Tween20/PBS and incubated in the recommended dilution of protein specific antibody (p-NF- $\mathrm{kB}$ \#3033, TNF- $\alpha$ \#3707S, Cell Signaling Technology, Danvers, MA, USA, Hsp-70 \#ab31010, Hsp-90 \#ab13492, IL-6 \#ab25107, Abcam, Cambridge, UK, sGC- $\beta_{1} \# 160897$ Cayman Chemical, Ann Arbor, Michigan, USA) overnight at $4{ }^{\circ} \mathrm{C}$. After incubation with a horseradish peroxidaseconjugated anti-rabbit secondary antibody (GE Healthcare, Freiburg, Germany), proteins were visualized using the ECL plus Chemiluminescence Kit (GE Healthcare). For normalization, blots were re-probed with NF- $\mathrm{kB}$ (\#8242, Cell Signaling) and B-Actin (\#4967S, Cell 
Signaling). Relative changes in protein expression in IR injured retinae either with injection of ALF-186 or PBS were calculated in relation to the corresponding non-ischemic retinae.

Densitometric analysis of individual phosphorylation was performed using the Image-J open source software (ImageJ, Version 2.00-rc-44/1.50e, open source image processing software) comparing the relative changes in protein expression in IR injured retinae with each intervention and calculated in relation to the corresponding non-ischemic retinae.

\section{Real-time polymerase chain reaction (RT-PCR)}

From retinal tissue harvested $24 \mathrm{~h}$ after ischemia, total RNA from $1 / 4$ of retina was extracted using a columnpurification based kit (RNeasy Micro Kit, Qiagen, Hilden, Germany) according to the manufacturer's instructions. Reverse transcription was performed with $50 \mathrm{ng}$ of total RNA using random primers (High Capacity cDNA Reverse Transcription Kit, Applied Biosystems, Darmstadt, Germany). Real-time polymerase chain reactions (RT-PCR) were done with TaqMan $^{\odot}$ probe-based detection kit (TaqMan ${ }^{\circledR}$ PCR universal mastermix, Applied Biosystems, Darmstadt, Germany). Following primers were used: NF-kB \#Rn01399583_m1, CREB \#Rn02532082_g1, TNF- $\alpha$ \#Rn01525859_g1, IL-6
\#Rn01410330_m1, Hsp-70 \#Rn04224718_u1, Hsp-90 \#RN00822023_g1 (all from Applied Biosystems, Darmstadt, Germany). The PCR assays were then performed on a RT-PCR System (ABI Prism 7000, Applied Biosystems, Darmstadt, Germany) with the following cycling conditions: $95{ }^{\circ} \mathrm{C}$ for $10 \mathrm{~min}, 40$ cycles of $95{ }^{\circ} \mathrm{C}$ for $10 \mathrm{~s}$ and $60{ }^{\circ} \mathrm{C}$ for $1 \mathrm{~min}$. Reaction specificity was confirmed by running appropriate negative controls. Cycle threshold (CT) values for each gene of interest were normalized to the corresponding $\mathrm{CT}$ values for GAPDH $(\triangle C T)$. Relative gene expression in IR injured retinal tissue either with injection of ALF-186 or PBS was calculated in relation to the corresponding gene expression in the non-injured retinal tissue of each individual animal $(\Delta \Delta \mathrm{CT})$.

\section{Statistical analysis}

Data was analyzed using a computerized statistical program (SigmaPlot Version 11.0, Systat Software Inc., San Jose, CA, USA). The results are presented as means $( \pm \mathrm{SD})$ after normal distribution of data had been verified. One-way ANOVA for repeated measurements was used for between-group comparisons with post hoc Holm-Sidak test and Kruskal Wallis test for data with lack of normal distribution. $P<0.05$ was considered statistically significant.

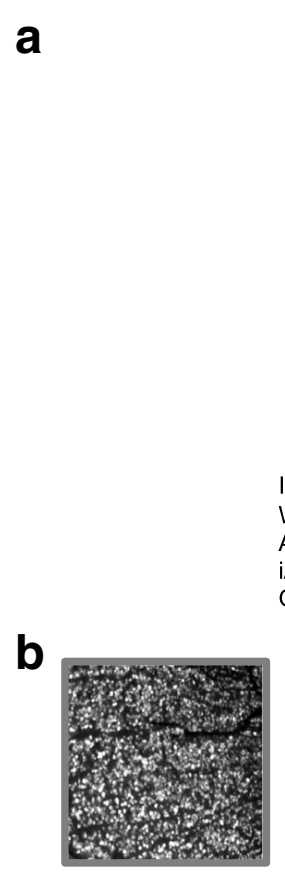

Water
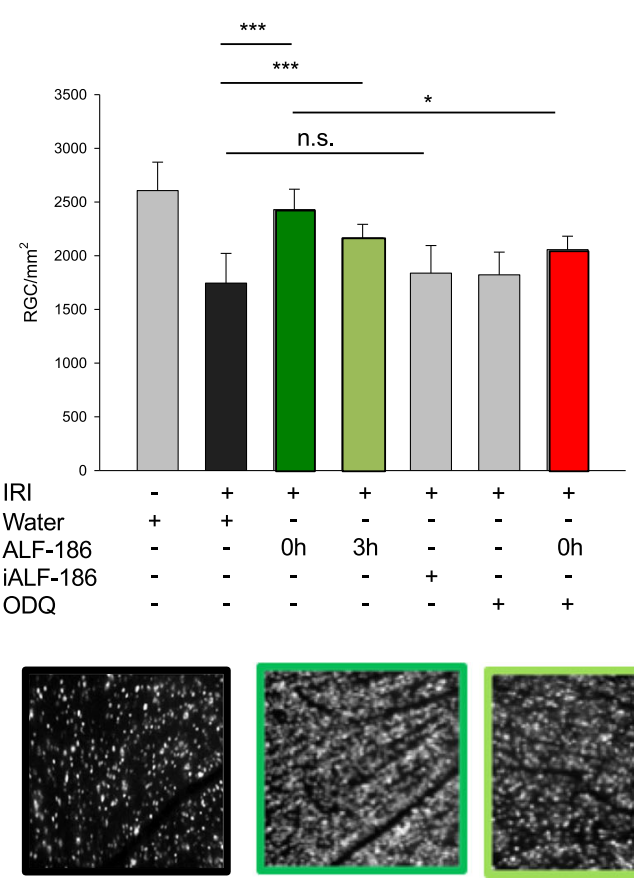

IRI

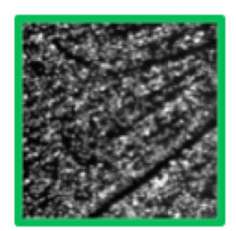

IRI+ALF-186 (0h)

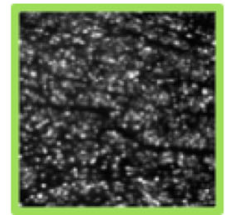

IRI+ALF-186 (3h)

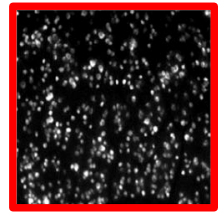

ODQ+IRI+ALF-186

Fig. 1 Influence of ALF-186 treatment on vital retinal ganglion cell count after ischemia reperfusion injury (IRI). a Quantification of retinal ganglion cell density (cells $/ \mathrm{mm}^{2}$, data are mean $\pm \mathrm{SD}, n=8, \mathrm{IRI}$ vs. IRI $+\mathrm{ALF}-1860 \mathrm{~h}$ and $3 \mathrm{~h},{ }^{* * *}=p<0.001$ and $\mid \mathrm{RI}+\mathrm{ALF}-1860 \mathrm{~h}$ vs. $\mid \mathrm{RI}+\mathrm{ALF}-186+\mathrm{ODQ}$, ${ }^{*}=p$ $<0.05$; n.s. = not significant). $\mathbf{b}$ Representative flat mount images $(n=8)$ of fluorogold-labeled retinal ganglion cells 7 days after IRI, immediate and delayed (3 h) ALF-186 treatment, inactivated ALF-186 treatment and SGC inhibition with ODQ 


\section{Results}

\section{ALF-186 treatment protects RGC against ischemia} reperfusion injury (IRI)

Retinal IRI decreased the density of retinal ganglion cells by approximately 40\% (Fig. 1, Col. 1 and 2; IRI $1808 \pm$ 262 vs. untreated $\left.2503 \pm 295,{ }^{* * *}=p<0.001\right)$. Immediate $(0 \mathrm{~h})$ ALF-186 treatment almost completely neutralized this effect (untreated $2503 \pm 295$ vs. IRI + ALF-186 $0 \mathrm{~h}$ $2499 \pm 377$ ). Even delayed ALF-186 application (3 h) reduced RGC loss significantly (IRI $1808 \pm 262$ vs. IRI \pm ALF-186 3 h $2202 \pm 239, * * *=p<0.001)$. In contrast, administration of inactivated ALF-186 did not influence RGC survival compared to untreated animals. The sGC inhibitor ODQ was able to partly inactivate the neuroprotective effect of ALF-186 (IRI + ALF-186 2499 \pm 377 vs. ODQ + IRI + ALF-186 $\left.2126 \pm 1680,{ }^{*}=p<0.05\right)$.

\section{ALF-186 stimulates sGC- $\beta_{1}$ protein expression}

In the following experiment, we determined sGC- $\beta_{1}$ protein expression after IRI and ALF-186 treatment. ALF186 increased sGC- $\beta_{1}$ protein expression significantly. Concerning the time point of enucleation, major effect was detectable after $24 \mathrm{~h}$. Performing enucleation $48 \mathrm{~h}$ after IRI the effect on sGC- $\beta_{1}$ was reduced. (Fig. 2a, b; $* * *=p<0.001 ; * *=p<0.01)$. To confirm ALF's mechanism of action on $\mathrm{sGC} \beta_{1}$, we next performed experiments using the sGC inhibitor ODQ prior to IRI and enucleated the eyes after 24 hours. We found that ODQ alone had no influence on sGC phosphorylation following IRI. However, ODQ reduced ALF-186 mediated protein expression of sGC in Western Blot. This effect was confirmed by densitometrical analysis where ODQ abolished the ALF-186 mediated increase of $\mathrm{sGC} \beta_{1}$-protein expression completely (Fig. 2c, d). Figure 3a shows the upregulation of $\mathrm{sGC}$ in the inner retina of ALF-186 treated eyes after IRI. Co-expression with Brn-3a confirmed the expression of sGC in RGCs. Quantification of sGC revealed a significant increase due to ALF-186 treatment, especially during IRI, while iALF-186 attenuated sGC signal (Fig. 3b; ${ }^{* * *}=p<0.001$ ).

\section{ALF-186 reduces IRI-induced increase of NF-KB mRNA expression and protein phosphorylation}

Next, we have examined the influence of ALF-186 on transcription factors NF- $\mathrm{kB}$ and CREB by RT-PCR and Western Blot analysis. ALF-186 reduced IRI-mediated
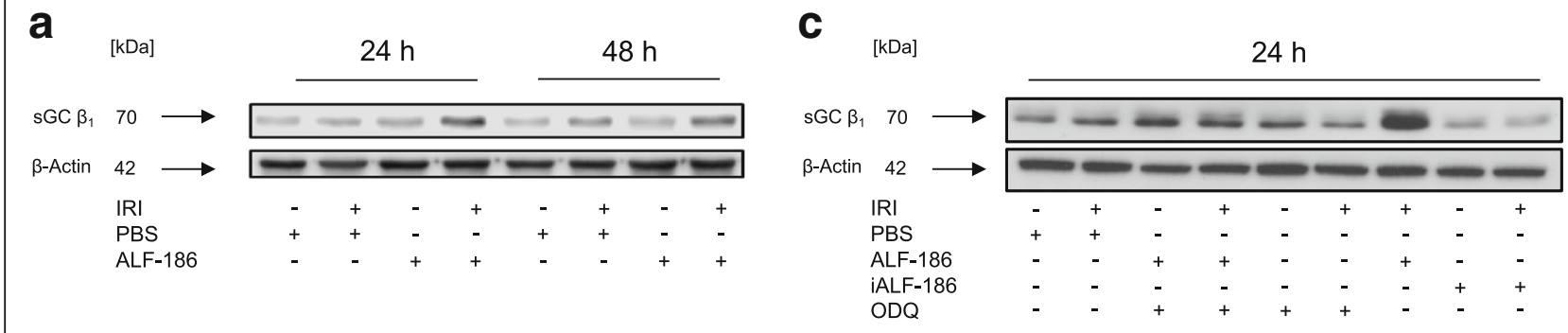

b

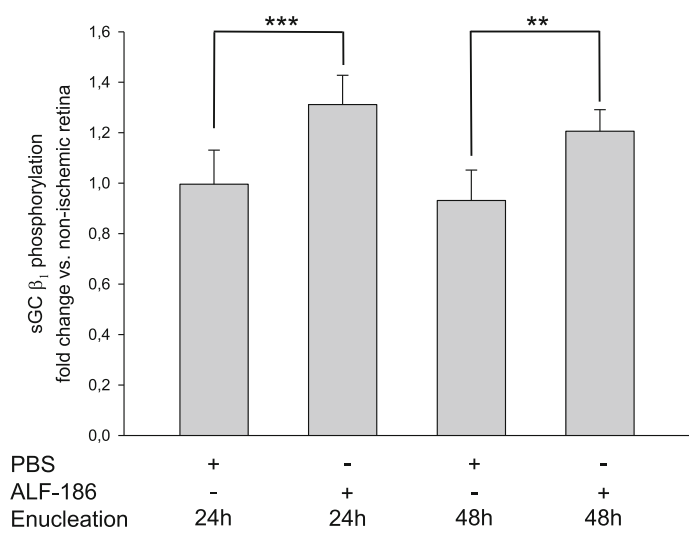

d

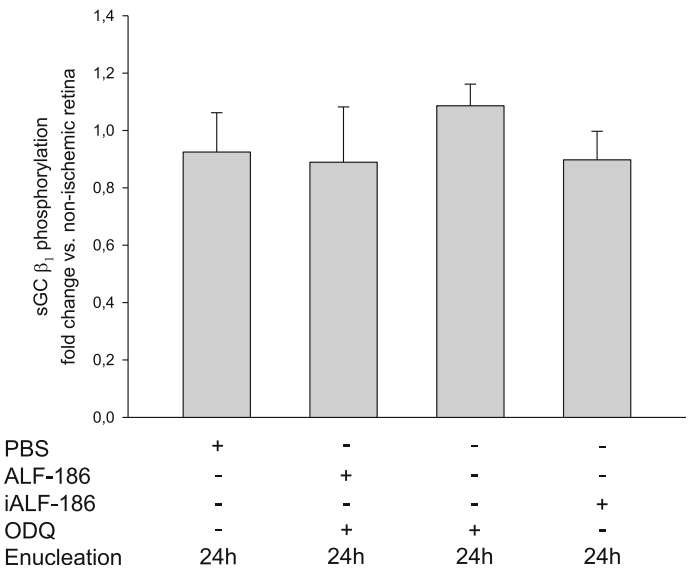

Fig. 2 Effect of ALF-186 treatment on the expression of soluble guanylyl cyclase (sGC) $\beta_{1}$. a Representative western blot image $(n=8)$ showing the increase of SGC $\beta_{1}$ compared to $\beta$-Actin after immediate ALF-186 postconditioning. Enucleation was performed either 24 or $48 \mathrm{~h}$ after IRI. b Densitometric analysis of $n=8$ western blots for $\mathrm{SGC} \beta_{1}$ after ALF-186 (data are mean \pm SD; IRI vs. IRI + ALF-186 $24 h$, *** $=p<0.001$ and IRI vs. IRI + ALF-186 $48 \mathrm{~h},{ }^{* *}=p<0.01$ ). c Representative western blot image and densitometric analysis of $n=8$ Western Blots for sGC $\beta_{1}$ compared to $\beta$-Actin after ODQ inhibition and ALF-186, ODQ inhibition alone and ODQ-inhibition and iALF-186. Enucleation was performed $24 \mathrm{~h}$ after IRI. $\mathbf{d}$ Densitometric analysis of $n=8$ Western Blots for $\mathrm{SGC} \beta_{1}$ after ALF-186 in the presence of ODQ 


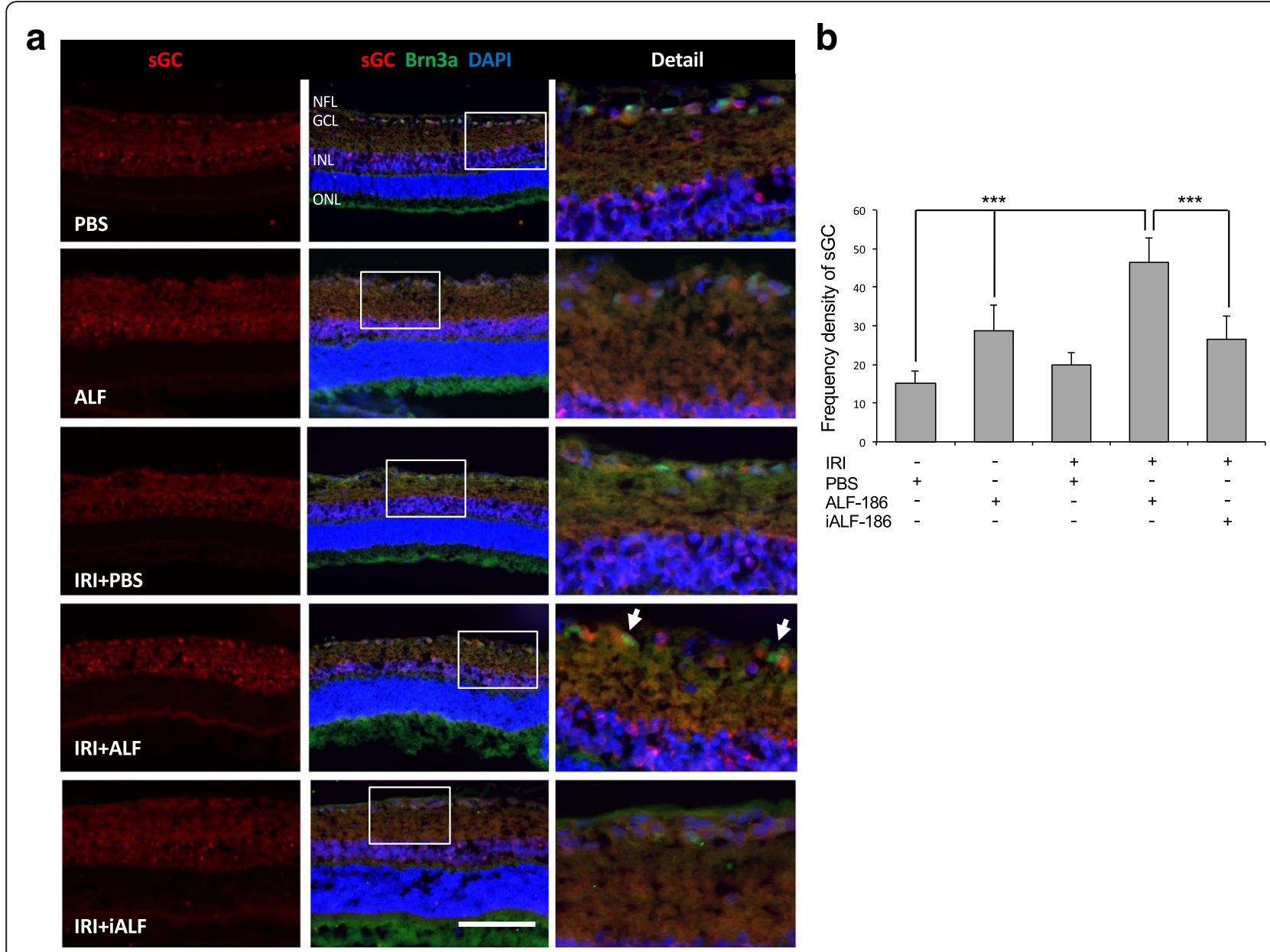

Fig. 3 ALF-186 treatment increases SGC expression in retinal ganglion cells due to IRI a sGC and Brn3a/DAPI co-expression in the retina after unilateral IRI in the presence and abscence of ALF-186/iALF-186 or PBS. Cross-sections of the retinae $24 \mathrm{~h}$ after unilateral IRI. In controls with and without IRI SGC was only positive as a baseline expression. ALF-186 vehicle group and IRI + ALF-186 treatment resulted in an increased expression of SGC, mostly in the inner nuclear layer and the retinal ganglion cells as co-staining with Brn3a demonstrates (right column, forth image, arrows). Inactivated ALF-186 did not show any significant effects concerning SGC expression compared to control groups. (Scale bar, $50 \mu \mathrm{m}$; Abbreviations: $\mathrm{NFL}=$ nerve fiber layer, $\mathrm{GCL}=$ ganglion cell layer, $\mathrm{INL}=$ inner nuclear layer and $\mathrm{ONL}=$ outer nuclear layer). $\mathbf{b}$ Frequency density of sGC protein expression in the groups as quantified by histogram analysis (*** $=p<0.001$ PBS vs. ALF-186 amd IRI + ALF-186 and IRI + ALF-186 VS. IRI + iALF-186)

increase of NF- $\mathrm{kB}$ mRNA expression as well as NF- $\mathrm{kB}$ protein phosphorylation significantly (Fig. $4 \mathrm{a} ;{ }^{* * * *}=p<$ $0.001 ; *=p<0.05)$. At least in part, this effect can be repealed by sGC inhibition with ODQ (Fig. 4a; ${ }^{*}=p<$ 0.05 ; Fig. $4 \mathrm{c}, \mathrm{d}$; ${ }^{*}=p<0.05$ ).

Additionally, ALF-186 reduces IRI-induced increase of CREB mRNA, but not in a significant way. Surprisingly, pretreatment with ODQ before IRI and treatment with ALF-186 decreased CREB mRNA expression while ODQ had no effect at all (Fig. 4b).

\section{ALF-186 reduced IRI-induced increase of tumor necrosis factor alpha (TNF- $\alpha$ )}

TNF- $\alpha$ is a cytokine that has been identified as a key regulator in inflammatory response. Therefore, we analyzed TNF- $\alpha$ mRNA and protein expression by RTPCR and Western Blot. IRI increased TNF- $\alpha$ mRNA substantially. This effect was partially antagonized by sGC-inhibition (Fig. 5a; ${ }^{* * * *}=p<0.001 ; *=p<0.05$ ). Western Blot analysis confirmed this effect: ALF-186 decreased IRI induced increase of TNF- $\alpha$ protein expression while ODQ was able to reverse expression partly (Fig. 5b, c; ${ }^{* * *}=p<0.001 ; * *=p<0.01$ and $*=p<0.05$ ). TNF- $\alpha$ was detectable in retinal cross sections of IRIeyes mainly in the area of the ganglion cell layer. Quantification of TNF- $\alpha$ revealed a significant decrease due to ALF-186 treatment during IRI. (Fig. 5d; $p<0.001$ ). Serum levels of TNF- $\alpha$ protein revealed a substantial increase due to IRI (Fig. 5e; ${ }^{* * * *}=p<0.001$ ), while the administration of ALF-186 significantly decreased TNF- $\alpha$ 


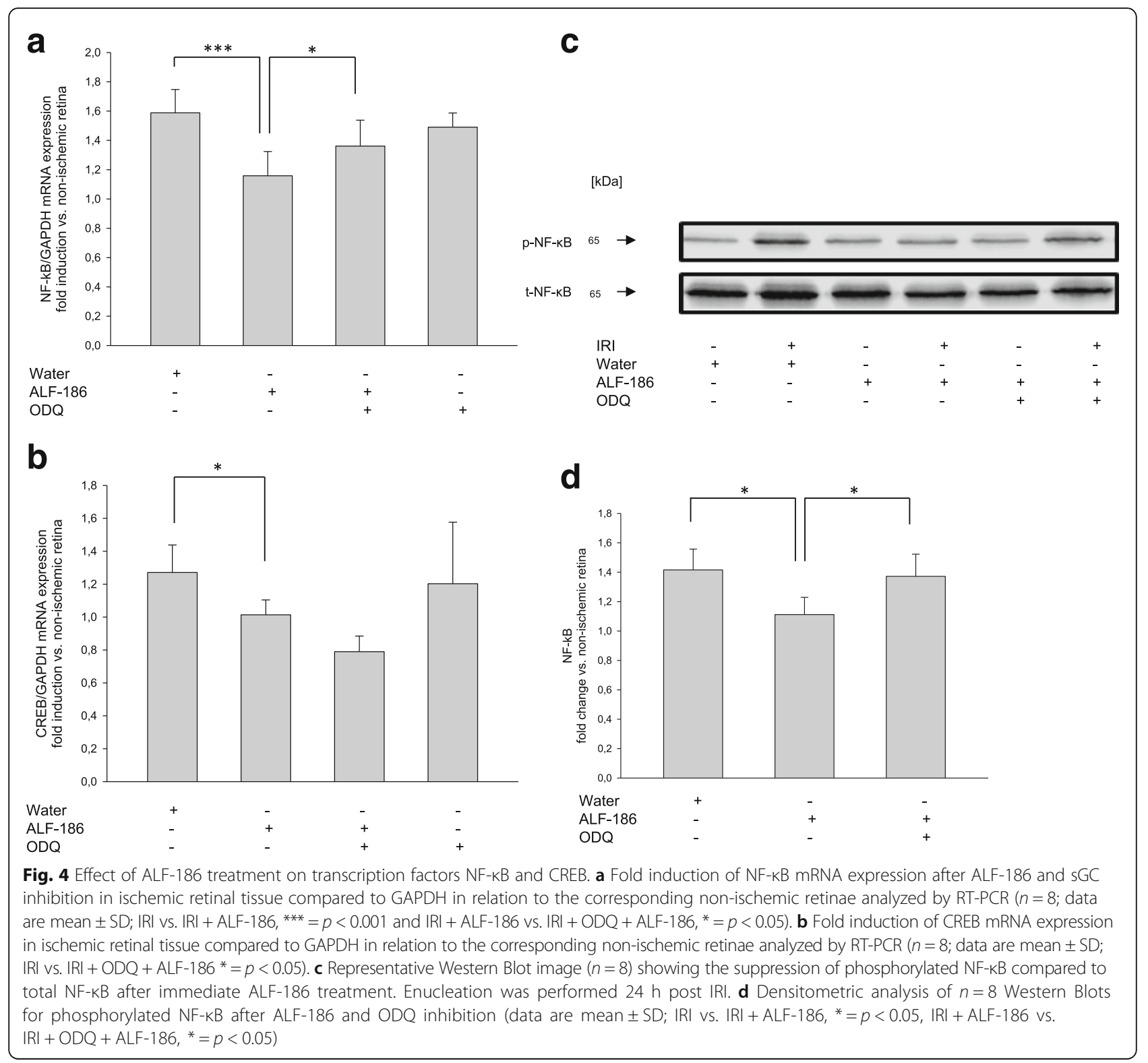

protein levels in the rats' serum (Fig. 5e; $*=p<0.01$ ). Inhibition of sGC via ODQ inhibited the ALF-186 mediated effect regarding TNF- $\alpha$ serum protein expression (Fig. 5e; ${ }^{*}=p<0.05$ ).

ALF-186 reduced IRI-induced increase of Interleukin-6 (IL-6) In the next step, we examined the influence of ALF-186 on the pro-inflammatory cytokine IL- 6 . ALF-186 caused a rigorous drop of IRI induced IL- 6 mRNA expression (Fig. 6a; $* * *=p<0.001$ ). However, in a weakened form, this effect was also observed in IL-6 protein expression (Fig. $6 \mathrm{~b}+\mathrm{c}$; ${ }^{*}=p<0.05$ ). sGC inhibition diminished the ALF-186 mediated IL-6 mRNA decrease (Fig. 6a; ${ }^{* * *}=p$ $<0.01)$. IL-6 expression was predominantly present in the ganglion cell layer of retinal cross sections and slightly pronounced in IRI + PBS-eyes compared to ALFtreated eyes (Fig. 6d). Quantification of IL-6 revealed a significant decrease due to ALF-186 treatment during IRI (Fig. 6d; $p<0.05$ ). Serum levels of IL-6 protein revealed a substantial increase due to IRI (Fig. 6e; $* * * *$ 0.001 ), while the administration of ALF-186 significantly decreased TNF- $\alpha$ protein levels in the rats' serum (Fig. 6e; $* *=p<0.01$ ). Inhibition of $\mathrm{sGC}$ via ODQ inhibited the ALF-186 mediated effect regarding TNF- $\alpha$ serum protein expression (Fig. 6e; ${ }^{*}=p<0.05$ ).

\section{ALF-186 attenuates heat shock response}

In a further step, we analyzed the impact of IRI and ALF-186 on heat shock proteins 70 and 90. ALF-186 increased HSP90 mRNA and protein expression (Fig. 7a; 


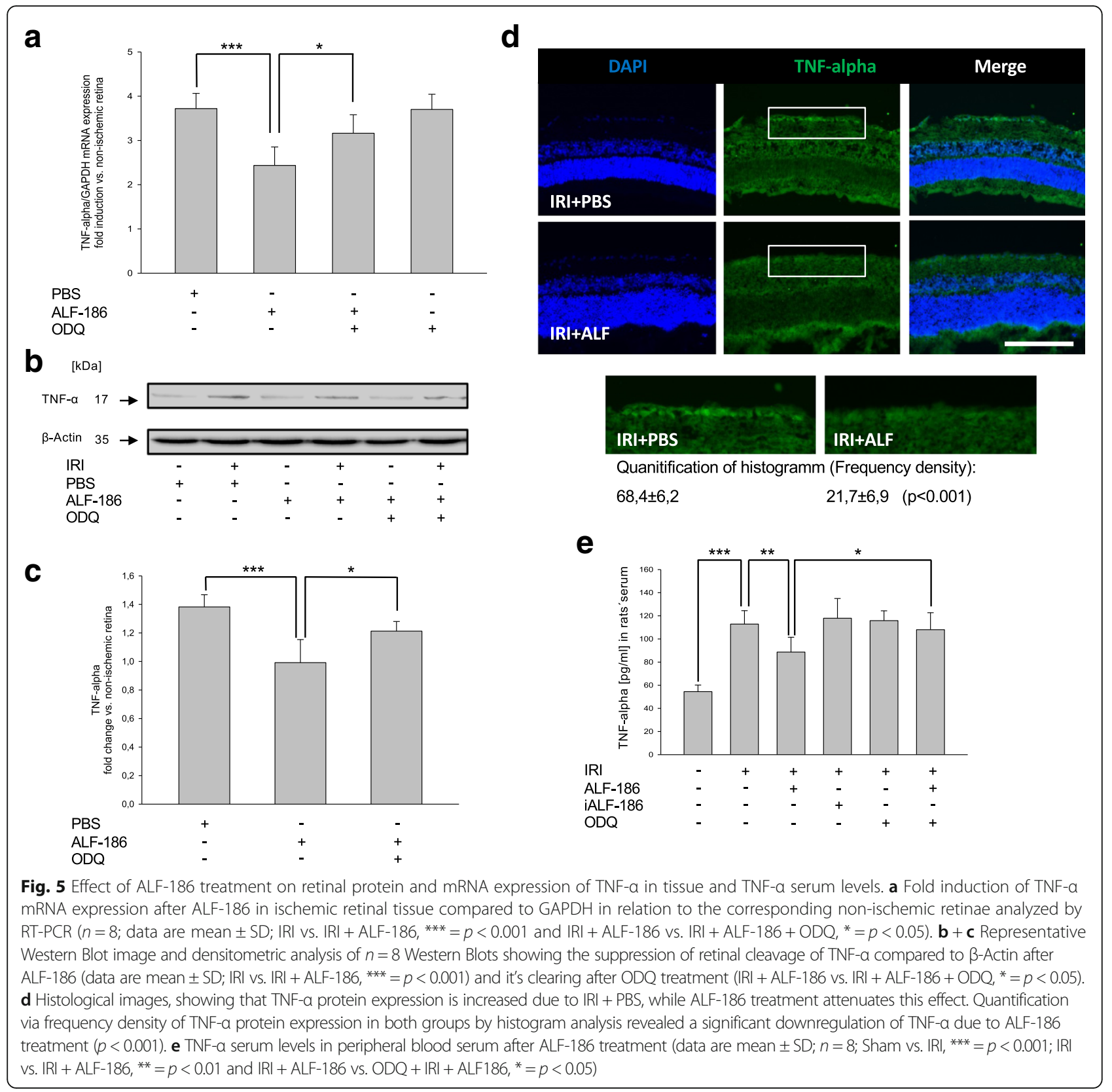

$* * *=p<0.001$; Fig. 7b, c; $*=p<0.05)$. HSP-90 was expressed predominantly in RGC of IRI + ALF-treated eyes, as shown by double-immunohistochemistry with Brn-3a (Fig. 7d). In contrast, HSP70 mRNA and protein expression was reduced significantly by ALF-186 (Fig. 8a; ${ }^{* * *}=p<0.001$; Fig. 8b, c; ${ }^{*}=p<0.05$ ).

Interestingly, inhibition of $\mathrm{sGC}$ did not alter heat shock response at all, neither in mRNA nor in protein expression.

\section{Discussion}

The main findings of this in vivo study can be summarized as follows: (1) ALF-186 mediates neuroprotective properties via the soluble guanylate cyclase- $\beta_{1}$ subunit (sGC- $\beta_{1}$ ) in RGC. (2) ALF-186 diminished the IRI induced NF- $\mathrm{kB}$ expression and phosphorylation in RGC. (3) ALF186 treatment reduced expression of inflammatory cytokines Interleukin-6 (IL-6) and tumor necrosis factor alpha (TNF- $\alpha$ ) in neuronal tissue and in rats' serum. (4) ALF186 modified IRI-mediated heat shock response. (5) Inhibition of sGC- $\beta_{1}$ abrogated ALF's effects regarding NF- $\mathrm{kB}$, IL- 6 and TNF- $\alpha$ expression, finally leading to a decrease of retinal ganglion cells. (6) However, ODQ did not affect the heat shock response significantly.

Various studies have shown that low-dose carbon monoxide-given either before or after injury-may 


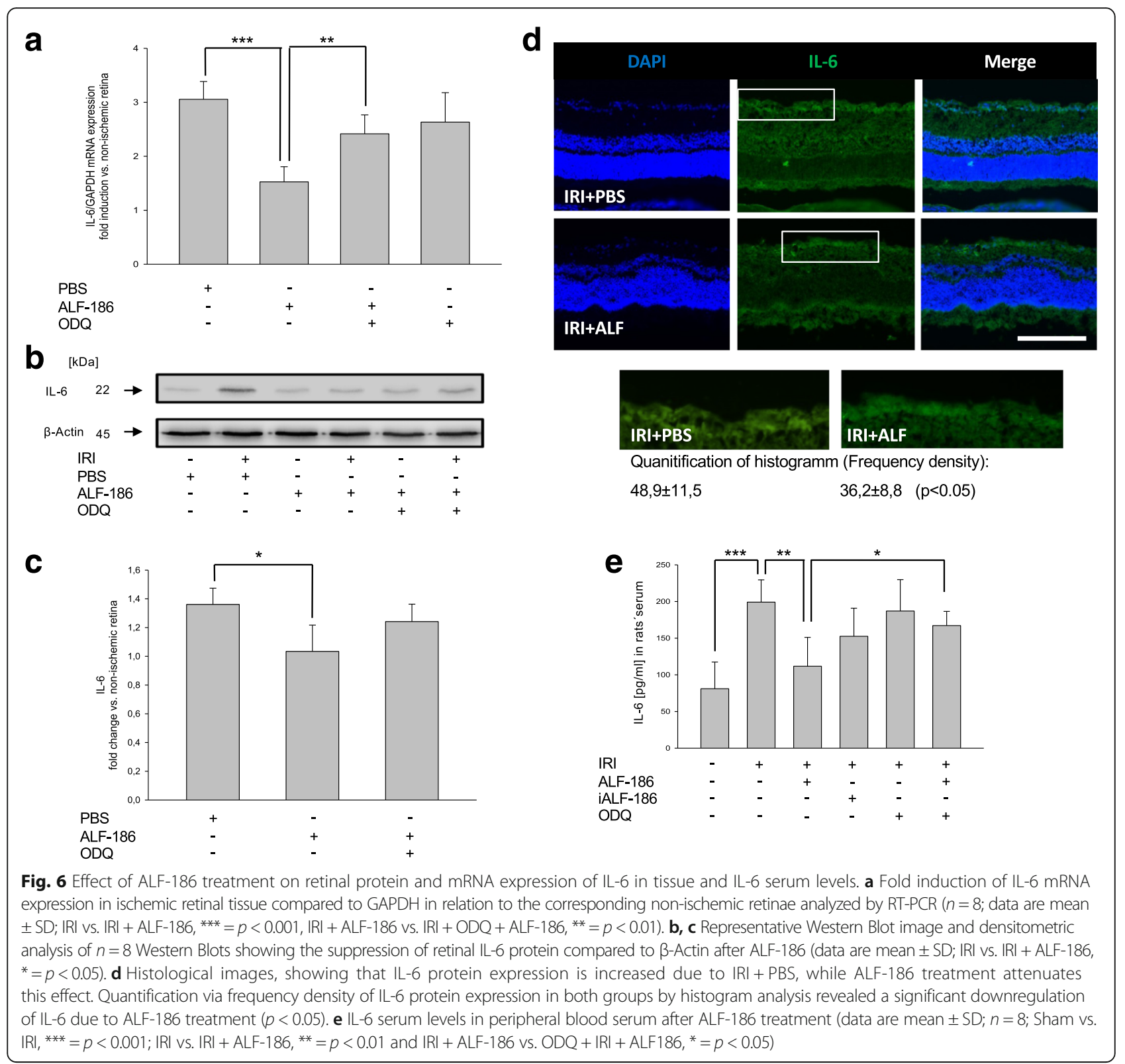

decrease organic failure: As a potential therapeutic agent, it has impact on different organic systems and mediates protection in lung, liver, kidney and cardiovascular system [17-19]. Well known as a potentially toxic agent at high doses, little is known about the protective mechanism of low-dose $\mathrm{CO}$ affecting neuronal tissue, especially not when given as a therapeutic and noninhalational agent. Our data show that sGC- $\beta_{1}$ seems to play a pivotal role in promoting ALFs' neuroprotective effects. Moreover, other cellular processes seemed to be involved concerning ALF's protective effect. Own research demonstrated that MAPK p38 is decisively involved in ALFs' action on neuronal apoptosis and neuroprotection. Vieira et al. demonstrated in their study with primary cultured neurons that pre-treatment with $\mathrm{CO}$ exerted protection implicating sGC, $\mathrm{NO}$ and mitochondrial $K_{\text {ATP }}$ channels [20]. Moreover, in a recently published work, Vieira et al. demonstrated the effectiveness of the CORM A1 in improving neurogenesis and preventing neuronal apoptosis [21]. Several studies have shown that carbon monoxide exerts protective effects due to IRI in different organic tissues by activation of sGC $[2,22,23]$.

Furthermore, Wang et al. exposed mice to $\mathrm{CO}$ immediately after middle cerebral artery occlusion and detected reduced brain damage and proved Nrf2 pathway as a crucial part of the mechanism [24]. Another aspect was explored by Mahan et al. who claim changes in 


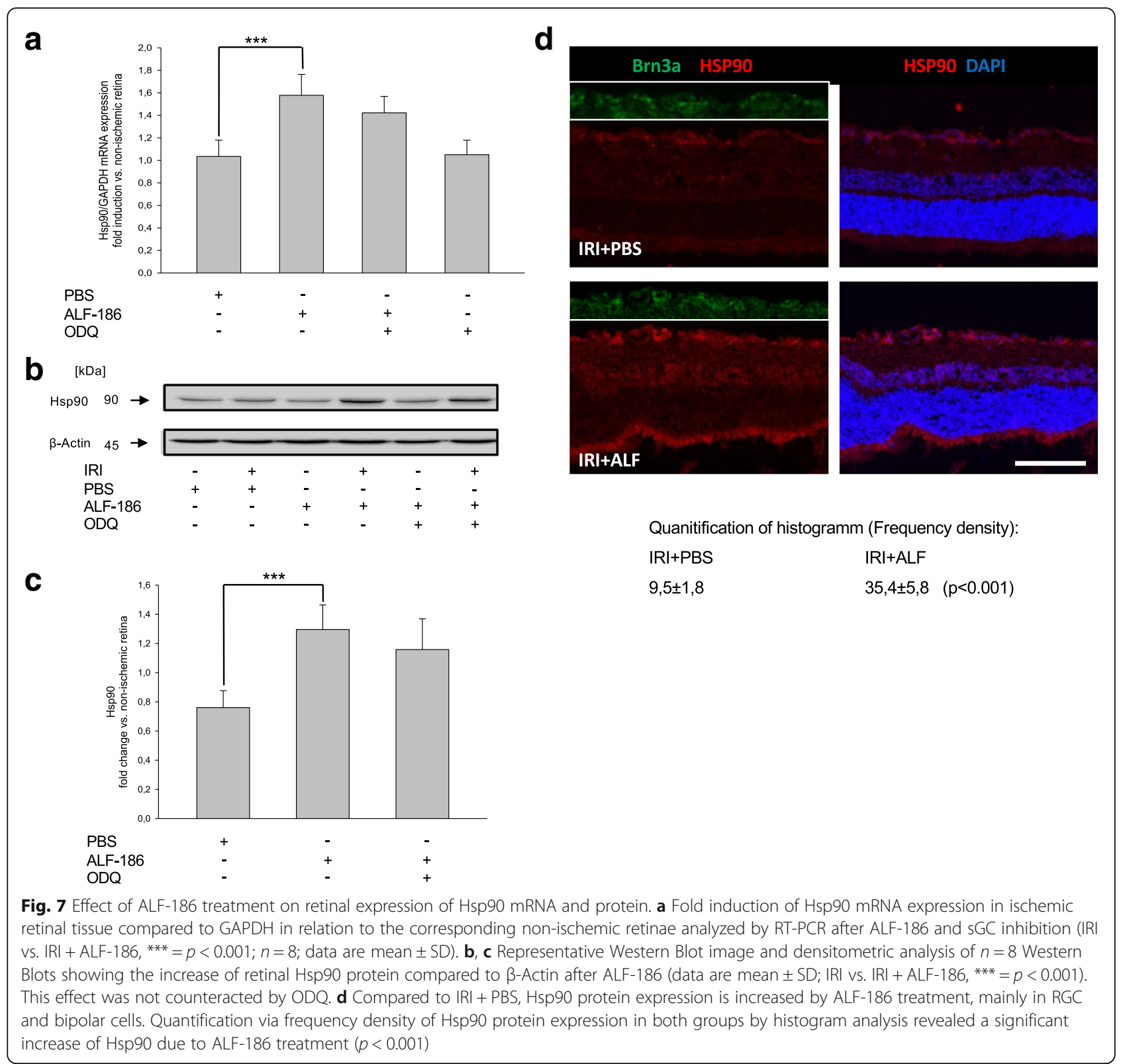

neurometabolic substrate, especially lactate, responsible for CO's neuroprotective effect [25].

Regarding neuronal injury, the impact of carbon monoxide on pro-inflammatory NF- $\mathrm{kB}$ has not been investigated so far. However, Wei et al. attribute carbon monoxide hepato-protective effects in part to NF- $\mathrm{kB}$. In their investigation with hepatic IRI in rats, CORM-2 inhibited the activity of NF- $\mathrm{kB}$ leading to decreased serum levels of pro-inflammatory cytokines IL-6 and TNF- $\alpha$ [26]. Qin et al. demonstrated the impact of CORM on the inflammatory response in a model of septic mice. CORM administration was able to inhibit sepsis-induced NF- $\mathrm{kB}$ activation in lung and liver and reduced serum cytokine levels of IL- 6 and TNF- $\alpha$ [5].
For the first time, we describe the influence of $\mathrm{CO}$ on NF- $\mathrm{kB}$ phosphorylation and pro-inflammatory cytokine expression in neuronal tissue. According to the study of hepatic IRI we found a down-regulation of NF- $\mathrm{KB}$ and, consequently, IL- 6 and TNF- $\alpha$ following ALF-186 treatment not only in neuronal tissue but in the serum, too, demonstrating the systemic effects of ALF-186.

The impact of carbon monoxide on neuronal inflammation has not been well analyzed. Our results showed a reduction of IRI induced IL- 6 and TNF- $\alpha$ expression. These finding are in accordance with Biermann et al. who described similar effect on TNF- $\alpha$ when $\mathrm{CO}$ was inhaled prior to retinal IRI [16]. However, the antiinflammatory effect of carbon monoxide due to IRI in 
a

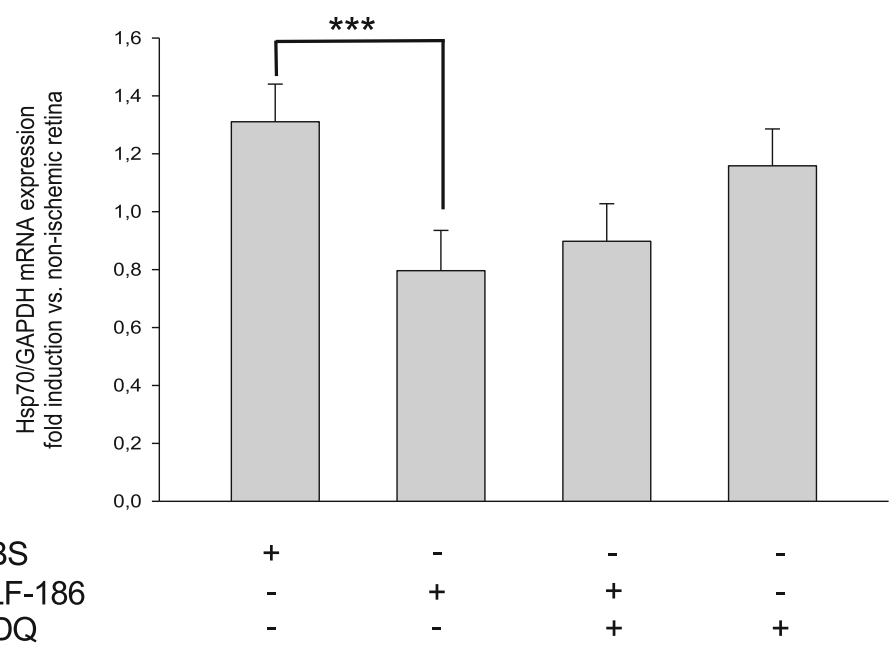

b $\quad[\mathrm{kDa}]$

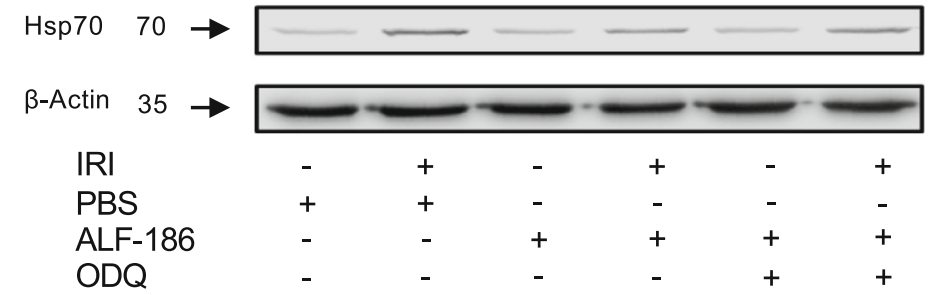

C

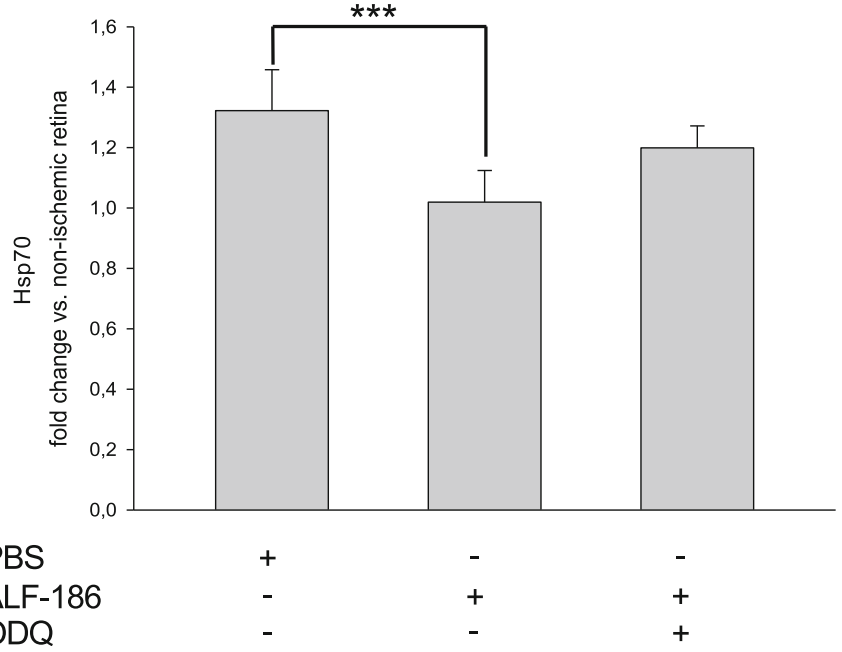

Fig. 8 Effect of ALF-186 on retinal expression of Hsp70 mRNA and protein. a Fold induction of Hsp70 mRNA expression in ischemic retinal tissue compared to GAPDH in relation to the corresponding non-ischemic retinae analyzed by RT-PCR after ALF-186 and sGC inhibition (IRI vs. IRI + ALF$186,{ }^{* * *}=p<0.001 ; \boldsymbol{n}=8$; data are mean $\pm \mathrm{SD}$ ). $\mathbf{b}$, c Representative Western Blot image and densitometric analysis of $n=8$ Western Blots showing the decrease of retinal Hsp70 protein compared to $\beta$-Actin after ALF-186 (data are mean \pm SD; IRI vs. IRI +ALF-186, ${ }^{* * *}=p<0.001$ )

non-neuronal tissue and organs is well described in literature. Nakao et al. explored in their transplant study not only jejunal circular muscle contractility after intestinal transplantation in rats, but also expression of inflammatory cytokines in the graft muscularis. They demonstrated that carbon monoxide improved muscle dysmobility and also decreased transplant induced IL-1 $\beta$ and IL-6 upregulation [2]. Neto et al. performed orthotopic kidney transplation in rats and demonstrated reduced mRNA levels of 
pro-inflammatory cytokines IL-1ß, IL-6, and TNF- $\alpha$ in kidney grafts of $\mathrm{CO}$ treated recipients [4]. Moreover, inhalative $\mathrm{CO}$ treatment may affect these cytokines in heart and lung grafts $[3,6]$.

In the present study, we also have examined the impact of ALF-186 regarding the heat shock response. The heat shock response is characterized by the cellular expression of heat shock proteins in response to harmful events like ischemia, heat or toxins. Heat shock proteins are described to weaken harmful stressors and play a crucial role in neuronal cytoprotection, affecting cell death and immune response pathways [27, 28]. Various studies indicate that Hsp-70 mediates anti-inflammatory effects and decreases inflammatory cytokine production. For example, increased levels of Hsp-70 are detected in cerebral IRI $[29,30]$. Neuroprotective effects are described for Hsp-90 as well [31, 32]. However, the interactions and interdependencies between the Hsps are not well studied, especially not in neuronal inflammation. However, upon dissociation from their common transcription factor HSF, Hsp-90 is able to induce Hsp-70 indicating opposite effects [33]. Our data show that ALF-186 increased Hsp-90 expression after retinal IRI and, interestingly, a decrease in the expression of Hsp70. This result are partly in contrariety to the findings by Biermann et al., showing an induction of $\mathrm{Hsp}-70$ when inhaled carbon monoxide was applied prior to retinal IRI [16]. The mode and time-point of application may be responsible for these divergent results. It is tempting to speculate that ALF-186 is able to suppress cytokine production and provide robust protection inhibiting Hsp-70 and consecutively increasing Hsp-90.

Furthermore, we demonstrated that the specific sGC inhibitor ODQ was able to abrogate the effect of ALF186 on transcription factor NF- $\mathrm{KB}$ as well as proinflammatory cytokines IL- 6 and TNF- $\alpha$, while no significant changes were observed concerning the heat shock response. Finally, ODQ mitigated ALF's neuroprotective effect leading to an increased loss of retinal ganglion cells. This result is in accordance to Nakao et al. They demonstrate that sGC inhibitor ODQ was able to abrogate the beneficial effect of carbon monoxide during cold intestinal ischemia reperfusion injury associated with intestinal transplantation in rats. In accordance to our study ODQ also inhibited transplantassociated increase of pro-inflammatory IL-6 [2].

It is very interesting that neither ALF-186 nor IRI alone are able to increase retinal sGC expression, although the combination of both clearly increases sGC. We speculate about a "second hit" phenomenon, in which both parts are needed to induce sGC expression. ODQ preferentially binds to the prosthetic heme part of sGC, thus inhibiting both, activity and subsequently its de-novo expression. As known throughout the literature,
sGC activation may alter vascular smooth muscle cell proliferation, platelet aggregation and consequently blood flow [15, 34]. We cannot exclude, that ALF-186 additionally activates smooth vascular muscle sGC in the retina. This would potentially lead to an increase of retinal blood flow due to $\mathrm{sGC}$-mediated vasodilation and could alter the reperfusion injury [35].

Our model has some limitations: The rats' retina is a very small organ and even though desirable, it is not possible to perform many assays with one retina. In order not to kill to many animals for just one experiment, we chose to perform nRNA and protein expression assays, rather than activity assays, although activity-especially of sGC-would elucidate the role of ALF-186 in the context of IRI even more.

\section{Conclusion}

In conclusion, the carbon monoxide-releasing molecule ALF-186 was able to reduce IRI mediated inflammation, by upregulating sGC- $\beta 1$, as well as suppressing the proinflammatory transcription factor NF- $\mathrm{kB}$ and CREB and its downstream cytokines IL- 6 and TNF- $\alpha$ in neuronal tissue and systemically in the rats' serum. Furthermore, ALF-186 differentially regulated the heat shock response, thus proposing a novel target in neuronal IRI.

\begin{abstract}
Abbreviations
AMC: Activated microglia; CO: Carbon monoxide; CORM: Carbon monoxide releasing molecule; CREB: CAMP responsive element binding protein;

DMSO: Dimethylsulfoxid; FG: Fluorogold; GCL: Ganglion cell layer; HSP: Heat shock protein; IL-6: Interleukin 6; MAPK: Mitogen activated protein kinase; NF-KB: Nuclear factor KB; ODQ: SGC inhibitor; PBS: Phosphate buffered saline; RGC: Retinal ganglion cell; sGC: Soluble guanylate cyclase, IRI, ischemiareperfusion injury; TNF-a: Tumor necrosis factor-a
\end{abstract}

\section{Acknowledgements}

The authors thank Heide Marniga for technical assistance.

The article processing charge was funded by the German Research Foundation (DFG) and the Albert Ludwigs University Freiburg in the funding programme Open Access Publishing.

\section{Funding}

This work was conducted at the Department of Anesthesiology and Intensive Care and the Eye Center, Medical Center - University of Freiburg, Faculty of Medicine, Freiburg, Germany and granted by The German Research Foundation (DFG, Grants: for Ulrich Goebel Go 2158/3-1 and for Julia Biermann Bi 1567/2-1). The funder (DFG) had no role in study design, data collection and analysis, decision to publish or preparation of the manuscript.

\section{Availability of data and materials}

All data generated or analyzed during this study are included in this published article.

\section{Authors' contributions}

FU conducted the experiments, helped with data analysis and evaluation, wrote the manuscript, and approved the final version of this manuscript. $\mathrm{CH}$ conducted the experiments, helped with data analysis and evaluation and approved the final version of this manuscript. HB helped with the data analysis and evaluation, was an advisor in the management of the study and approved the final version of this manuscript. CCR provided the CORM ALF-186 (which is not available commercially), helped with data analysis and evaluation and approved the final version of this manuscript. NS helped with 
data analysis and evaluation, edited the manuscript and approved the final version of this manuscript. UG designed the study, is responsible for data analysis and evaluation, wrote the manuscript and approved the final version of this manuscript. JB designed the study, conducted the immunohistochemical experiments, helped with data analysis and evaluation, wrote the manuscript, and approved the final version of this manuscript.

\section{Competing interests}

The co-author Carlos C. Romão is a co-founder, administrator and scientific officer of the company Alfama Lda. where he has equity interests. Carlos C. Romão is an inventor of Patent-No.: US 2011/0038955 A1 2011, where ALF186 exemplifies the protection of the stomach against NSAID generated ulcers by the administration of CORMs, and is therefore irrelevant for the matter of the present article. The drug profile of ALF-186 is published in detail in: Dalton Transactions DOI: 10.1039/c2dt32174b.

We have the following interests: Alfama Ltd. provided support in the form of supplying Carlos C. Romão with the ALF-186 compound - which is not commercially available-but did not have any additional role in the study design, data collection and analysis, decision to publish, or preparation of the manuscript. The specific role of this authors is articulated in the 'author contributions' section. These conflicts of interest do not alter the adherence of all authors to all the Journal of Neuroinflammation policies on sharing data and materials. The remaining authors declare no competing financial interests.

\section{Consent for publication}

All authors agreed to the publication of this manuscript.

\section{Ethics approval and consent to participate}

All procedures involving animals concurred with the statement of The Association for Research in Vision and Ophthalmology for the use of animals in research in accordance with the ARRIVE guidelines and were approved a priori by the Committee of Animal Care of the University of Freiburg (Permit No: 35-9185.81/G-11/81)

\section{Publisher's Note}

Springer Nature remains neutral with regard to jurisdictional claims in published maps and institutional affiliations.

\section{Author details}

${ }^{1}$ Department of Anesthesiology and Critical Care, Medical Center, University of Freiburg, Faculty of Medicine, University of Freiburg, Hugstetter Strasse 55, D-79106 Freiburg, Germany . ${ }^{2}$ Eye Center, Medical Center - University of Freiburg, Faculty of Medicine, University of Freiburg, Freiburg, Germany. ${ }^{3}$ Instituto de Tecnologia Química e Biológica-António Xavier, Universidade Nova de Lisboa, Oeiras, Portugal. ${ }^{4}$ Alfama Ltd., Instituto de Biologia Experimental e Tecnológica, IBET, Oeiras, Portugal.

\section{Received: 19 August 2016 Accepted: 18 June 2017}

\section{Published online: 27 June 2017}

\section{References}

1. Costa NRD, Silva RO, Nicolau LAD, Lucetti LT, Santana APM, Aragão KS, et al. Role of soluble guanylate cyclase activation in the gastroprotective effect of the $\mathrm{HO}-1 / \mathrm{CO}$ pathway against alendronate-induced gastric damage in rats. Eur J Pharmacol. 2013;700:51-9.

2. Nakao A, Kimizuka K, Stolz DB, Neto JS, Kaizu T, Choi AMK, et al. Carbon monoxide inhalation protects rat intestinal grafts from ischemia/reperfusion injury. Am J Pathol. 2003:163:1587-98.

3. Nakao A, Toyokawa H, Abe M, Kiyomoto T, Nakahira K, Choi AMK, et al. Heart Allograft Protection with Low-Dose Carbon Monoxide Inhalation: Effects on Inflammatory Mediators and Alloreactive T-cell Responses. Transplantation. 2006:81:220-30.

4. Neto JS. Protection of transplant-induced renal ischemia-reperfusion injury with carbon monoxide. Am J Physiol Renal Physiol. 2004;287:F979-89.

5. Qin W, Zhang J, Lv W, Wang X, Sun B. Effect of carbon monoxide-releasing molecules II-liberated CO on suppressing inflammatory response in sepsis by interfering with nuclear factor kappa B activation. Gao H, editor. PloS ONE. Public Library of Science; 2013;8:e75840.

6. Kohmoto J, Nakao A, KAIZU T, TSUNG A, Ikeda A, TOYOKAWA H, et al. Low dose carbon monoxide inhalation prevents ischemia/reperfusion injury of transplanted rat lung grafts via inhibition of ERK1/2. J Surg Res. 2006;130:208.

7. Kaizu T, Ikeda A, Nakao A, Tsung A, Toyokawa H, Ueki S, et al. Protection of transplant-induced hepatic ischemia/reperfusion injury with carbon monoxide via MEKJERK1/2 pathway downregulation. American Journal of Physiology-Gastrointestinal and Liver Physiology. American Physiological Society; 2008;294:G236-44.

8. Otterbein LE, Mantell LL, Choi AMK. Carbon monoxide provides protection against hyperoxic lung injury. Am J Physiol. 1999;276:L688-94.

9. Otterbein LE, Bach FH, Alam J, Soares M, Tao Lu H, Wysk M, et al. Carbon monoxide has anti-inflammatory effects involving the mitogen-activated protein kinase pathway. Nat Med. 2000;6:422-8.

10. Petrache I, Otterbein LE, Alam J, Wiegand GW, Choi AM. Heme oxygenase-1 inhibits TNF-alpha-induced apoptosis in cultured fibroblasts. Am J Physiol Lung Cell Mol Physiol. 2000;278:L312-9.

11. Frost RB, Farrer TJ, Primosch M, Hedges DW. Prevalence of traumatic brain injury in the general adult population: a meta-analysis. Neuroepidemiology. Karger Publishers; 2013;40:154-9.

12. Lopez AD, Mathers CD, Ezzati M, Jamison DT, Murray CJL. Global and regional burden of disease and risk factors, 2001: systematic analysis of population health data. Lancet. 2006;367:1747-57.

13. Langlois JA, Rutland-Brown W, Wald MM. The epidemiology and impact of traumatic brain injury: a brief overview. J Head Trauma Rehabil. 2006;21:375-8.

14. Queiroga CSF, Tomasi S, Wideroe M, Alves PM, Vercelli A, Vieira HLA. Preconditioning triggered by carbon monoxide (CO) provides neuronal protection following perinatal hypoxia-ischemia. Borlongan CV, editor. PloS ONE. Public Library of Science; 2012;7:e42632.

15. Dasgupta A, Bowman L, D’Arsigny CL, Archer SL. Soluble Guanylate Cyclase: A New Therapeutic Target for Pulmonary Arterial Hypertension and Chronic Thromboembolic Pulmonary Hypertension. Clin Pharmacol Ther. 2015;97:88-102.

16. Biermann J, Lagrèze WA, Dimitriu C, Stoykow C, Goebel U. Preconditioning with inhalative carbon monoxide protects rat retinal ganglion cells from ischemia/reperfusion injury. Invest. Ophthalmol Vis Sci. The Association for Research in Vision and Ophthalmology; 2010;51:3784-91.

17. Tomiyama K, Ikeda A, Ueki S, Nakao A, Stolz DB, Koike Y, et al. Inhibition of Kupffer Cell-mediated early proinflammatory response with carbon monoxide in transplant-induced hepatic ischemia/reperfusion injury in rats. Hepatology. Wiley Subscription Services, Inc., A Wiley Company; 2008;48:1608-20.

18. Ruan Y, Wang L, Zhao Y, Yao Y, Chen S, Li J, et al. Carbon monoxide potently prevents ischemia-induced high-mobility group box 1 translocation and release and protects against lethal renal ischemiareperfusion injury. Kidney Int. 2014;86:525-37.

19. Stein AB, Bolli R, Dawn B, Sanganalmath SK, Zhu Y, Wang O-L, et al. Carbon monoxide induces a late preconditioning-mimetic cardioprotective and antiapoptotic milieu in the myocardium. J Mol Cell Cardiol. 2012;52:228-36.

20. Vieira HLA, Queiroga CSF, Alves PM. Pre-conditioning induced by carbon monoxide provides neuronal protection against apoptosis. J Neurochem. 2008;107:375-84.

21. Almeida AS, Sonnewald U, Alves PM, Vieira HLA. Carbon monoxide improves neuronal differentiation and yield by increasing the functioning and number of mitochondria. J Neurochem. 2016;138:423-35.

22. Fujimoto $H$, Ohno M, Ayabe $S$, Kobayashi $H$, Ishizaka N, Kimura $H$, et al. Carbon monoxide protects against cardiac ischemia-reperfusion injury in vivo via MAPK and Akt-eNOS pathways. Arterioscler Thromb Vasc Biol. American Heart Association, Inc; 2004;24:1848-53.

23. Sandouka A, Fuller BJ, Mann BE, Green CJ, Foresti R, Motterlini R. Treatment with CO-RMs during cold storage improves renal function at reperfusion. Kidney Int. 2006;69:239-47.

24. Wang B, Cao W, Biswal S, Doré S. Carbon Monoxide-Activated Nrf2 Pathway Leads to Protection Against Permanent Focal Cerebral Ischemia. Stroke. 2011:42:2605-U369.

25. Mahan VL, Zurakowski D, Otterbein LE, Pigula FA. Inhaled carbon monoxide provides cerebral cytoprotection in pigs. Meisel A, editor. PloS ONE. Public Library of Science; 2012;7.

26. Wei $Y$, Chen $P$, de Bruyn M, Zhang W, Bremer E, Helfrich W. Carbon monoxide-Releasing Molecule-2 (CORM-2) attenuates acute hepatic ischemia reperfusion injury in rats. BMC Gastroenterol. BioMed Central. 2010; 10:42. doi:10.1186/1471-230X-10-42. PMID:20444253. PMCID:PMC2873601.

27. Yenari MA, Liu JL, Zheng Z, Vexler ZS, Lee JE, Giffard RG. Antiapoptotic and anti-inflammatory mechanisms of heat-shock protein protection. Ann N Y Acad Sci. 2005;1053:74-83. 
28. Kelly S, Yenari MA. Neuroprotection: Heat Shock Proteins. Curr Med Res Opin. 2002;18:555-60.

29. Banecka-Majkutewicz Z, Grabowski M, Kadzinski L, Papkov A, Wegrzyn A, Banecki B. Increased levels of antibodies against heat shock proteins in stroke patients. Acta Biochim Pol. 2014;61:379-83.

30. He D, Song X, Li L. Geranylgeranylacetone protects against cerebral ischemia and reperfusion injury: HSP90 and eNOS phosphorylation involved. Brain Res. 2015;1599:150-7.

31. Meng J-L, Mei W-Y, Dong Y-F, Wang J-H, Zhao C-M, Lan A-P, et al. Heat shock protein 90 mediates cytoprotection by $\mathrm{H}_{2} \mathrm{~S}$ against chemical hypoxiainduced injury in PC12 cells. Clin Exp Pharmacol Physiol. Blackwell Publishing Ltd; 2011;38:42-9.

32. Biermann J, Lagrèze WA, Schallner N, Schwer Cl, Goebel U. Inhalative preconditioning with hydrogen sulfide attenuated apoptosis after retinal ischemia/reperfusion injury. Mol Vis. 2011;17:1275-86.

33. Kim N, Kim JY, Yenari MA. Anti-inflammatory properties and pharmacological induction of Hsp70 after brain injury. Inflammopharmacology. SP Birkhäuser Verlag Basel; 2012;20:177-85.

34. Bettaga N, Jaeger R, Duennes S, Groneberg D, Friebe A. Cell-specific impact of nitric oxide-dependent guanylyl cyclase on arteriogenesis and angiogenesis in mice. Angiogenesis. Springer Netherlands; 2015;18:245-54.

35. Mori A, Namekawa R, Hasebe M, Saito M, Sakamoto K, Nakahara T, et al. Involvement of prostaglandin I-2 in nitric oxide-induced vasodilation of retinal arterioles in rats. Eur J Pharmacol. 2015;764:249-55.

Submit your next manuscript to BioMed Central and we will help you at every step:

- We accept pre-submission inquiries

- Our selector tool helps you to find the most relevant journal

- We provide round the clock customer support

- Convenient online submission

- Thorough peer review

- Inclusion in PubMed and all major indexing services

- Maximum visibility for your research

Submit your manuscript at www.biomedcentral.com/submit
Biomed Central 